7 Voigt ED, Bahn D. Metabolism and pulse rate in physically handicapped when propelling a wheelchair up an incline. Scand f Rehab Med 1969;1: $101-6$.

8 Hjeltnes N. Oxygen uptake and cardiac output in graded arm exercises in paraplegics with low level spinal lesions. Scand $\mathcal{F}$ Rehab Med 1977;9:10713.

9 Hulleman K-D, List M, Matthes D, Wiese G, Zika D. Spiroergometric and telemetric investigations during the XX1 International Stoke Mandeville Games 1972 in Heidelberg. Paraplegia 1975;13:109-23.
10 Davis GM, Shephard RJ. Strength training for wheelchair users. $\mathrm{Br} \mathcal{F}$ Sports Med 1990;24:25-30.

11 Davis GM, Plyley MJ, Shephard RJ. Gains of cardiorespiratory fitness with arm-cranking training in spinally disabled men. Can $\mathcal{f}$ Sport Sci 1991;16:64-72.

12 Veeger HEJ, Yahmed MH, van der Woude LHV, Charpentier P. Peak oxygen uptake and maximal aerobic power output of Olympic wheelchairdependent athletes. Med Sci Sports Exerc 1991;23:1201-9.

\title{
A national strategy for the promotion of physical activity
}

Three years ago, as part of the Health of the Nation strategy, the Government appointed a Physical Activity Task Force. It was charged with developing detailed national strategies for the promotion of physical activity. It was asked to consider gaps in current knowledge and to suggest means of filling them. Its remit also included the development of proposals and recommendations for taking the work forward and for monitoring progress in achieving specific targets.

The task force began its work in the confidence that the international scientific literature supported the case for exercise, and was sufficient for evidence based action. It perceived that the health benefits to be gained from a physically active lifestyle are real, well documented, and widely accepted as an important public health measure. Its notice was drawn to very many studies confirming that physical inactivity is very deleterious to health and a major risk factor for many chronic diseases, including coronary heart disease, stroke, obesity, high blood pressure, and osteoporosis. This evidence is drawn from epidemiological, clinical, and physiological studies.

The proposals from the task force were contained in a consultation paper "More People More Active More Often". This document, and the replies which it elicited from a wide variety of interested organisations, led to the government's strategy statement for physical activity, ${ }^{2}$ published earlier this year (19 March). The statement contains a summary of the recommendations from the task force and sets three key objectives (see below).

The consultation paper informed the Health Education Authority's new campaign, ACTIVE for LIFE, launched on the same day as publication of the strategy. The campaign represents the start of a well funded promotion designed to encourage physical activity as part of a healthy lifestyle. This will be a more sustained campaign than has previously been attempted.

It is only recently that the scientific case for the importance of regular participation in physical exercise has been accepted as sound and compelling by key professional bodies. A Working Party of the Royal College of Physicians of England, convened in $1989,{ }^{3}$ examined this evidence, recognised its importance and based a series of recommendations upon it. The American Heart Association recognized physical inactivity as a major risk factor for development of coronary heart disease only in $1993 .^{4}$ The general population appears to have accepted the message more rapidly: in $199075 \%$ of adults responding to the Allied Dunbar National Fitness Survey accepted that regular exercise conferred health benefits, though there had not been a corresponding change in exercise behaviour.

\section{New recommendations}

About the same time as the first meeting of the task force a new recommendation regarding physical activity was released in the United States by the American College of
Sports Medicine, the Centers for Disease Control, and the President's Council for Physical Fitness and Sport Recommendation (1993)..$^{5}$ The recommendation has been reinforced by the recent publication of the US Surgeon General's report. ${ }^{6}$ This recommendation proposes that "every American adult should accumulate 30 minutes or more of moderate intensity physical activity over the course of most days of the week. Because most Americans do not presently meet the standard described above, almost all should strive to increase their participation in moderate and/or vigorous physical activity". The task force was satisfied that the evidence in favour of moderate intensity exercise was sufficient to serve as a basis for target setting and was likely to be effective for the majority of people. It accepted the US recommendation and it has been incorporated into the government strategy. It places the emphasis on epidemiological evidence, on the weekly volume of physical activity, and on the importance of overall energy expenditure. An element of doubt remains regarding the answers to three questions.

(1) Will it be confirmed that moderate intensity exercise is adequate for all important health benefits? This is a reasonable interpretation of existing evidence. However, we can expect this to be challenged from time to time by new findings suggesting that it is "vigorous" intensity exercise which is important after all.

(2) Does the same benefit accrue if time spent exercising is an accumulation of short bouts? It has been suggested that the accumulation of several shorter bouts of exercise (say three bouts of 10 minutes) may be as beneficial as 30 minutes of sustained activity. ${ }^{7}$ Certainly the approach is attractive to those who wish to promote physical activity.

(3) Can habitual levels of physical activity be measured and documental reliably over time? This will continue to present significant practical difficulties. Without such evidence the monitoring of long term interventions will prove problematic and important critical answers will remain elusive.

The Allied Dunbar National Fitness Survey (ADNFS) ${ }^{8}$ measured physical activity, fitness, and attitudes towards and beliefs about physical activity. The findings suggested that something has to be done. About one third of the adult population between 16 and 74 years of age was sedentary, reporting no physical activity of moderate intensity or above, that is, less than one occasion, on average, lasting at least 30 minutes per week in the previous four weeks (in other words, less than three occasions in a month). A quarter of young women aged between 16 and 24 were sedentary. Less than a third of all adults achieved an acceptable level of moderate intensity physical activity as recommended in the published strategy. The task force received reassurances that population shifts in exercise behaviour had been brought about in 
Australia, the United States, and Finland and that changes are possible and justified. The ADNFS survey, together with the findings from the Health survey for England $1991^{9}$ and $1992,{ }^{10}$ had supplied the knowledge base necessary for setting targets and for devising a positive health promotion strategies. The successful conduct of these surveys showed that a means of monitoring changes in the level of participation in physical activity was available. The task force proposed a $10 \%$ reduction in the proportion of adults who adopt a sedentary lifestyle and a $15 \%$ increase in the proportion of people who participate in regular physical activity by the year 2005 .

Government policy changed midway through the work of the task force; population targets were not published as part of the strategy but three were available as general objectives: "promote the value of moderate activity on a regular basis for sedentary people"; "inform people of the value of maintaining 30 minutes of moderate activity on at least five days a week for those who already take some moderate activity"; and "advocate, for those already taking some vigorous activity, the maintenance of a total of three periods of vigorous activity of 20 minutes a week".

\section{Are other government departments and agencies involved?}

Various organisations, including government departments, were represented through membership of the task force. This variety showed the level of enthusiasm for and the strength of the infrastructural support available for the introduction of a new public health policy. Several initiatives have been launched already, including an ambitious national strategy to increase the use of bicycles, with a target of quadrupling cycling for short journeys by 2005.
Effective interdepartmental and interagency collaboration will prove very important, but there are many potential partners. Are there just too many agencies for consistent messages to be conveyed and consistent local strategies developed? This emphasises the need for a central coordinating agency influential enough to sustain an effective alliance of all the involved agencies. Will the Health Education Authority receive encouragement to fulfil this role and hold together a robust alliance of all those wanting to play their part in promoting physical activity and active recreation? Changing the nation's lifestyle is a formidable challenge, but the case for effective action is overwhelming.

P H FENTEM

Stroke Association Professor of Stroke Medicine, University of Nottingham

1 Secretary of State for Health. The health of the nation. ( $\mathrm{Cm}$ 1523.) London: HMSO, 1991

2 Department of Health. Strategy on physical activity. London: Department of Health, 1996.

3 Royal College of Physicians. Medical aspects of exercise: benefits and risks. F R Coll Physicians Lond 1991;25:193-6.

4 Fletcher GF, Blair SN, Blumenthal J, Caspersen C, Chaitman B, Epstein $\mathrm{S}$, et al. AHA medical/scientific statement on exercise, benefits and recommendations for physical activity programs for all Americans. Circulation 1992;86:340-4.

5 Pate RR, Pratt M, Blair SH, Haskell WL, Macera CA, Bouchard C, et al. Physical activity and public health: a recommendation from the Centres for Disease Control and Prevention and the American College of Sports for Disease Control and Prevention an

6 US Public Health Service. Physical activity and health: $a$ report of the Surgeon General. Washington DC: US Government Printing Office, 1996. 7 Blair SN, Horton E, Leon AS, Lee I-M, Drinkwater BL, Dishman RK, et al. Physical activity, nutrition and chronic disease. Med Sci Sports Exerc 1996;28:335-49.

8 Activity and Health Research. Allied Dunbar national fitness survey: main findings. London, Sports Council and Health Education Authority, 1992.

9 White A, Nicholaas G, Foster K, Browne F, Carey S. Health survey for England 1991. OPCS Health Survey No 1. London: HMSO, 1993.

10 Breeze E, Maidment A, Bennett N, Flattley J, Carey S. Health survey for England 1992. OPCS Health Survey No 2. London: HMSO, 1994. 